\title{
RELAÇÃO ENTRE PARÂMETROS INFLUENCIADORES NA EFICIÊNCIA METALÚRGICA DE UM SEPARADOR MAGNÉTICO DE 750 GAUSS NO BENEFICIAMENTO DE COBRE E NÍQUEL *
}

\section{Resumo}

Gabriela Lemos Lages ${ }^{1}$

Os parâmetros influenciadores do processamento mineral para a concentração magnética, como granulometria das partículas, fluxo de alimentação da polpa, susceptibilidade magnética, atuam de forma conjunta em uma planta de beneficiamento. Foram analisadas amostras de polpa contendo sulfetos de níquel, cobre e metais preciosos em seis amostragens objetivando medir a eficiência de um separador magnético de tambor de 750 Gauss em um circuito primário de britagem. O rendimento do equipamento na planta industrial foi comparado com os parâmetros medidos em laboratório. Os resultados obtidos da granulometria médias das partículas da polpa para $80 \%$ e material passante (P80) foram: $150 \mu \mathrm{m}, 300 \mu \mathrm{m}$, $163,6 \mu \mathrm{m}, 146,1 \mu \mathrm{m}, 287,5 \mu \mathrm{m}$ e $164,8 \mu \mathrm{m}$, e a taxa de alimentação do circuito variou entre 30,2 tph e 55,2 tph, com pressão de lavagem média de $1,0 \mathrm{~kg} / \mathrm{cm} 3$. As amostras foram submetidas ao balanceamento metalúrgico utilizando o software Bilmat 9.5, após os resultados dos ensaios de caracterização: ICP-metais básicos, Satmagan e LECO-S. O percentual médio de recuperação magnética do laboratório foi de $80,1 \%$, enquanto na planta a média foi de $96,38 \%$, com a eficiência da planta em torno de 20,8\% superior à recuperação magnética em laboratório.

Palavras-chave: Separador Magnético; Eficiência Metalúrgica; Reciclador Magnético.

\section{RELATIONSHIP BETWEEN INFLUENCING PARAMETERS IN THE METALLURGICAL EFFICIENCY OF A 750 GAUSS MAGNETIC SEPARATOR IN THE BENEFIT OF COPPER AND NICKEL}

\section{Abstract}

The influential parameters of the mineral processing for the magnetic concentration, such as particle size, pulp flow-rate, magnetic susceptibility, operate together in a mineral treatment plant. Pulp samples containing precious metals, nickel and copper sulfides were analyzed in six surveys to measure the efficiency of a 750 Gauss magnetic separator in a primary crushing circuit. The efficiency of this equipment in the industrial site was compared with the parameters measured in the laboratory. The results obtained from the average particle size of the pulp for $80 \%$ passing material (P80) were: $150 \mu \mathrm{m}, 300 \mu \mathrm{m}, 163.6 \mu \mathrm{m}, 146.1 \mu \mathrm{m}, 287.5 \mu \mathrm{m}$ and $164.8 \mu \mathrm{m}$, and the circuit feed rate ranged from 30.2 tph and $55.2 \mathrm{tph}$, with an average for water's wash pressure of $1.0 \mathrm{~kg} / \mathrm{cm}^{3}$. The samples were submitted to metallurgical balancing using the software Bilmat 9.5, after the chemical test' results: ICP-basic metals, Satmagan and LECO-S. The average of the magnetic recovery rate of the laboratory was $80.1 \%$, while in the plant the average was $96.38 \%$, demonstrating that the plant efficiency was around $20.8 \%$ higher than the magnetic recovery in the laboratory.

Keywords: Magnetic Separator; Metallurgical Efficiency; Magnetic Recycler.

Discente do curso de Engenharia de Minas, Faculdades Integradas Pitágoras de Montes Claros, Montes Claros, Minas Gerais, Brasil. 


\section{INTRODUÇÃO}

Os separadores magnéticos (SM) compõem um dos métodos de concentração de uma planta de beneficiamento mineral qualquer, sendo este responsável pela retirada dos minérios de interesse ou concentrado dos rejeitos. Os SM fazem uso das propriedades magnéticas dos compostos minerais, separando-os em componentes mistos magnéticos e não-magnéticos dos minérios de valor (Wills \& Finch, 2016) [1]. "Em um ambiente homogêneo, os princípios das forças de separação magnética são proporcionais aos produtos do campo magnético externo e do vetor de gradiente deste campo" (Svoboda \& Fujita, p.786, 2003) [2].

Em um separador magnético existem várias forças competindo sob a ação das partículas. Entre estas, estão a força da gravidade, força de inércia, empuxo hidrodinâmico e as forças de superfície e internas das partículas [2].

A separação magnética das partículas, segundo Svoboda \& Fujita [2], apenas será possível se a soma das forças competitivas atuando sob as partículas forem menores que a soma das forças magnéticas de separação.

No presente trabalho, foram analisadas a porção magnética de amostras de minério em polpa de sulfeto de níquel e cobre, juntamente com outros metais preciosos do grupo platina (PGM) de uma planta industrial de beneficiamento da empresa $A$ no exterior. A composição mineralógica das amostras estudadas é formada por sulfetos disseminados durante uma possível formação basáltica, contendo os minerais de pirrotita, encontrada em forma de fragmentos; além de outros minerais como calcopirita, esfalerita, galena, pirita e marcassita (Rousell p. 7-9, 1983) [3]. Além destas, as mineralizações de zinco, chumbo, cobre, ouro e prata ocorrem em unidades de quartzo carbonatados [3]. A formação mineralógica das amostras descritas acima, e utilizadas nesta pesquisa, podem ter ocorrido de duas formas distintas, de acordo com o mesmo autor [3]: ou conforme a teoria da formação basáltica através do vulcanismo, ou através da teoria mais aceita, pelo impacto de um meteoro. Os fragmentos de sulfeto nesta formação geológica, podem ter-se dado através de zonas de "brecciamento" ricas em sulfetos, localizados no manto superior e na base da cratera transitória - local de explotação destes minérios [3]. A composição química típica dos depósitos de níquel, e advindas do run-of-mine, material que alimenta este circuito primário da planta A, contém cerca de $30,8 \%$ de cobre, $41,6 \%$ de níquel e $22,2 \%$ de enxofre que serão processados posteriormente nas operações de beneficiamento da empresa $A$.

Os resultados e discussões desta pesquisa consideraram os parâmetros metalúrgicos para o tratamento dos minerais de cobre e níquel. O modelo da planta A adota o fluxograma geral de tratamento de minérios, conforme a Figura 01, e abordado por Wills \& Finch [1] para o níquel e cobre. O material extraído é conduzido diretamente para a planta de tratamento, sendo, então, britado e moído no circuito primário e repassado para o primeiro separador magnético (1000 Gauss). O minério é então transferido para o segundo moinho de bolas 3B deste circuito, e repassado para o separador magnético de estudo (750 Gauss). O SM de 750 Gauss atua como secundário no circuito primário A, removendo metálicos "contaminantes" dos metais preciosos de valor comercial, antes de adentrar nos altos fornos e produzir os materiais metálicos para a refinaria. O SM de 750 Gauss é alimentado após a concentração magnética de um SM de 1000 Gauss, a fim de que atue como um refinamento da coleta do material magnético que não foi eficientemente separado durante a passagem pelo SM primário. A cominuição das partículas e suas respectivas liberações está diretamente relacionada com as eficiências de cada processo na planta industrial [1]. Segundo Wills \& Finch (2016, p. 06) "as partículas 
presas ao minério e ganga são denominadas middlings, e segundo, o processo de liberação destas só acontecem com subsequentes moagens". Contudo, a adesão entre minério e ganga é forte durante a cominuição, fazendo com que vários constituintes sejam deixados de lado nos limites dos grãos [1].

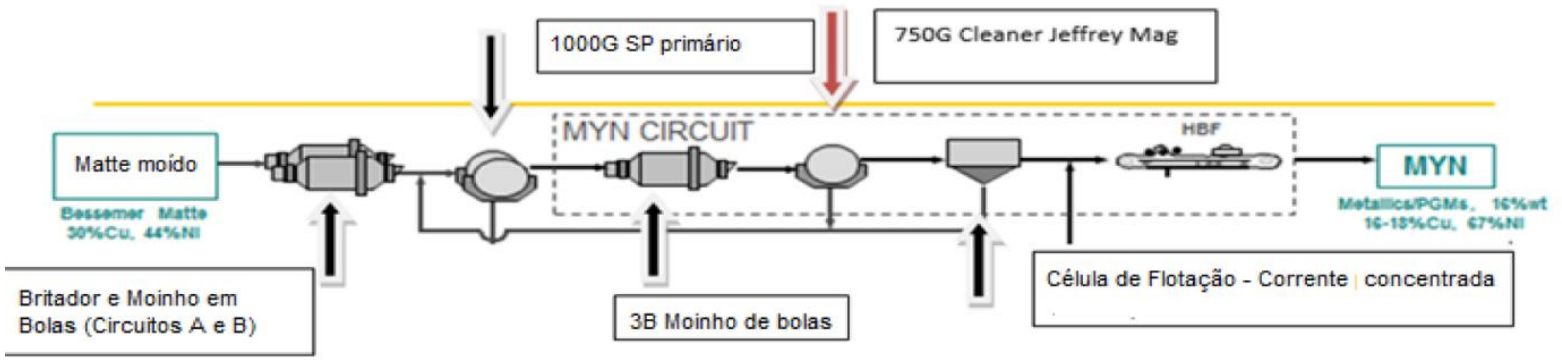

\footnotetext{
Legenda:

SP - Separador Magnético

G - Gauss (unidade de medida)

$\mathrm{Ni}$ - símbolo químico do elemento Níquel

Cu- símbolo químico do elemento Cobre

$\mathrm{S}$ - símbolo químico do elemento Enxofre

Bessemer Matte - mistura densa de vários metais de

sulfeto e alóis. Contém, em geral, $30,8 \% \mathrm{Cu} ; 41,6 \% \mathrm{Ni}$;

$22,2 \% \mathrm{~S}$

MYN - Alóide metálico contendo PGM (mistura de

metais preciosos)

HBF - Fluid Bed Roasters (parte do circuito designada

para início da flotação)
}

Figura 01: Circuito Primário da Planta de Beneficiamento A

Fonte: Empresa A

A partir do estudo bibliográfico a respeito dos processos de cominuição e separação magnética, foram elaborados os procedimentos e testes laboratoriais como metodologia desta pesquisa. Objetivou-se mensurar e avaliar o rendimento ou eficiência metalúrgica de um separador magnético secundário com eletroímã de tambor, classificado como reciclador metálico, com um campo magnético de 750 Gauss de intensidade da planta $A$. Os resultados seriam comparados com uma eficiência ideal medida em ensaios de laboratório; considerando-se outros parâmetros influenciadores neste processamento mineral, como a densidade das partículas, granulometria, entre outros fatores.

\section{MATERIAIS E MÉTODOS}

Previamente à coleta da polpa, foram criados procedimentos específicos de coleta das amostras para cada local de alimentação (feed), concentrado (magnetic concentrate ou middlings) e rejeito (tailings) para este separador magnético $\mathrm{A} e$ conforme o design do SM apresentado pela Figura 02. As partículas magnéticas da polpa ficam retidas pela imantação do tambor giratório, enquanto que pela saída do Underflow, o material não-magnético ou rejeito que já foi separado é, então, direcionado para outra saída do SM. As amostras da alimentação, concentrado e rejeito foram coletadas durante as datas 08, 14, 27, 28 de julho e 12 e 17 de agosto de 2016, totalizando seis pesquisas de amostragem. Para as amostras da alimentação (feed) e rejeito (tailings - estes se encontravam na caixa de descarga ou pump box do separador magnético A), foram coletados dois compósitos por vez; para o concentrado, apenas um compósito por vez, devido ao percentual de diluição da amostra. Buscou-se dessa forma, obter uma amostra mais representativa possível para cada local de coleta do SM. As amostragens também obedeceram a 
intervalos de 30 a 60 minutos entre cada coleta (três no total) e sob um período de 1 a 2 horas entre cada ponto de coleta do separador magnético (alimentação, concentrado e rejeito), em dias estáveis da operação da planta. A estabilidade das operações da planta foram monitoradas pela pesquisadora, conforme os relatórios diários da sala de controle de operações e a cada intervalo durante as amostragens, além do acompanhamento ao vivo da planta pelo sistema neural de dados da empresa A. A partir deste software no sistema, foi possível obter informações atualizadas da situação de cada parte do processamento, como por exemplo, a razão entre toneladas de minério alimentados por hora em cada equipamento; a quantidade de redes de água processada e de alimentação da polpa que estavam ligadas ao SM (a fim de se obter o percentual de sólidos ou densidade, além da diluição e vazão d'água); dentre outros fatores. Para cada data das coletas, as amostras em polpa de cada local do SM, foram filtradas, secadas na estufa, homogeneizadas, e separadas em massas menores utilizando um quarteador tipo Jones para a realização de testes posteriores. Todas as amostras foram submetidas para ensaios de caracterização, a fim de se obter o percentual de cada elemento químico dentro de cada tipo de amostra. Os testes químicos analíticos foram: ICP. Metais básicos (Laser Ablation - equipamento de espectrometria analítico que determina metais e outros compostos, a partir de partículas metálicas absorventes e contidas na amostra), Satmagan para compostos metálicos (teste químico analítico de separação de minerais pela sua propriedade magnética) e LECO-S (teste analítico para determinação de enxofre). As amostras e seus respectivos resultados obtidos através destes ensaios de caracterização, foram submetidos ao balanceamento metalúrgico de massas, utilizando a ferramenta Bilmat 9.5 através do software Excel.

Uma parte das amostras da alimentação (feed) foi utilizada para análises de distribuição granulométrica, utilizando as peneiras da série Tyler (tamanho em microns: $300,150,75,53,45,38,-38$ ), a fim de se verificar a influência dos tamanhos das partículas e seus respectivos graus de liberação, advindas do circuito primário de britagem e moagem do processamento da planta $A$ (especificamente do moinho de bolas $B$ - equipamento anterior à concentração magnética primária). Ainda, a cada rodada de coletas, uma segunda parte das amostras em polpa da alimentação e rejeito foi reservada para a execução do teste de separação magnética.

\subsection{Teste de Separação Magnética}

A fim de se calcular a porcentagem de recuperação magnética em laboratório, e, posteriormente, compará-la com os resultados de recuperação da planta, para a obtenção de eficiência do SM de estudo, foi feito o teste de separação magnética, conforme descrito a seguir. Tal procedimento indicou o quanto de material magnético (em massa e em porcentagem) que conseguiu ser separado do material não-magnético da polpa, dentre as amostras da alimentação, concentrado e de rejeito do SM. Para a execução deste procedimento em laboratório, utilizou-se uma célula de flotação contendo uma haste giratória, a fim de se homogeneizar a amostra da polpa, conforme a Figura 02. O procedimento inicia-se com a medição do peso da amostra em polpa, e em seguida inserida no recipiente da célula de flotação, respeitando a linha de volume previamente delimitada deste equipamento, para evitar o transbordamento da amostra. Ao despejar a polpa é necessário mexer circularmente e de forma suave o recipiente que contém a amostra, a fim de que não sobre material sólido no fundo deste. Logo em seguida, o bastão imantado 
envelopado é imerso neste mesmo recipiente contento a polpa, e então, liga-se o equipamento para a homogeneização do material e também para a fixação do material magnético no bastão. Aguardar aproximadamente três minutos para a primeira retirada do bastão magnético, desprendendo-o do envelope a fim de que se solte o material sólido magnético preso ao imã do bastão em um dos copos rotulados, conforme a Figura 02; e cerca de dois minutos de intervalo entre as próximas retiradas do material magnético, utilizando o mesmo procedimento com 0 bastão envelopado.

Desta forma, repetindo este último passo, o material magnético irá fixar-se no bastão a cada imersão e retirada deste de dentro da célula, restando apenas o material sólido não-magnético e água processada no recipiente original. Após o esgotamento de material magnético dentro da célula, observando a quantidade de sólidos fixada no bastão, o equipamento é desligado, a haste rotativa é erguida de dentro do recipiente, e então, limpa-se o restante do material sólido sob a haste, com água

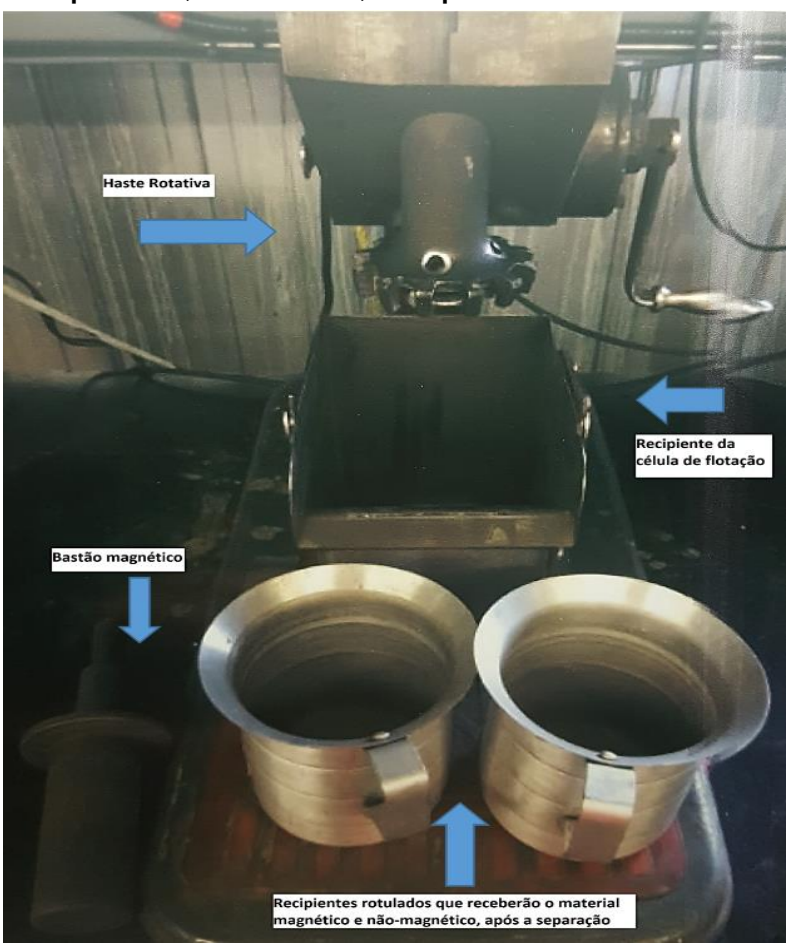

processada. Figura 02: Equipamento e materiais utilizados no teste de Separação Magnética Fonte: Autor

Então, os dois copos, um contendo material magnético e água processada; e outro contendo material não-magnético e água processada, são filtrados, secados na estufa, e então, os pesos das amostras já secas são registrados para os cálculos de porcentagem magnética da alimentação, do concentrado e do rejeito para o SM de estudo.

\section{RESULTADOS E DISCUSSÕES}

Um modelo generalizado de se representar a eficiência ou curva de partição é feito através da recuperação de uma corrente do circuito, geralmente utilizando o concentrado (middlings), como uma função de alguma propriedade do mineral [1]. Segundo Wills \& Finch [1], tal propriedade pode ser, por exemplo, a densidade, susceptibilidade magnética ou a granulometria. 
A Tabela 01 apresenta os resumos das recuperações magnéticas, resíduos de material magnético nos rejeitos (tailings) e taxa de fluxo da alimentação do SM de estudo, em toneladas por hora (vazão de alimentação).

Após a execução do teste de separação magnética em laboratório, é possível calcular a porcentagem de material magnético presente em cada corrente do SM: na alimentação, no concentrado e no rejeito.

Tabela 01. Resultados Obtidos das Amostragens, Resumo da Planta e Testes de Laboratório

\begin{tabular}{|c|c|c|c|c|c|c|c|c|c|}
\hline \multicolumn{4}{|c|}{\begin{tabular}{|l} 
Sólidos (\%) \\
\end{tabular}} & \multirow[b]{2}{*}{$\begin{array}{l}\text { Feed } \\
\mathrm{P}(80)^{1} \\
\text { micron } \\
\mathrm{s} \text { (um) }\end{array}$} & \multirow[b]{2}{*}{$\begin{array}{l}\text { Recupera- } \\
\text { ção } \\
\text { Magnética } \\
\text { no Con (\%) } \\
\text { (Lab) }\end{array}$} & \multirow[b]{2}{*}{$\begin{array}{l}\text { Resíduo } \\
\text { Mag. no } \\
\text { Rejeito } \\
\text { (\%) } \\
\text { (Lab) }\end{array}$} & \multirow[b]{2}{*}{$\begin{array}{l}\text { Recupera- } \\
\text { ção Mag. } \\
\text { no Conc. } \\
(\%) \text {. } \\
\text { (Planta) }\end{array}$} & \multirow[b]{2}{*}{$\begin{array}{l}\text { Eficiência } \\
\text { (Planta/Lab) } \\
\text { (\%) }\end{array}$} & \multirow[b]{2}{*}{$\begin{array}{l}\text { Vazão de } \\
\text { Alimenta- } \\
\text { ção (tph) }\end{array}$} \\
\hline $\begin{array}{l}\text { C } \\
\text { O } \\
\text { L } \\
\text { E } \\
\text { T } \\
\text { A } \\
\text { S }\end{array}$ & $\begin{array}{l}\text { Alimen- } \\
\text { tação }\end{array}$ & Conc. & $\begin{array}{l}\text { Re- } \\
\text { jeito }\end{array}$ & & & & & & \\
\hline 1 & 27.1 & 51 & 10.3 & 150 & 86.4 & 8.8 & 91.2 & 105.5 & 30.2 \\
\hline 2 & 40.2 & 72.4 & 11.3 & 300 & 74.3 & 15 & 98.2 & 132.2 & 53.9 \\
\hline 3 & 18.6 & 24.8 & 5.8 & 163.6 & 74.8 & 17.7 & 95.9 & 128.2 & 30.6 \\
\hline 4 & 19.1 & 29.2 & 12 & 146.1 & 75.9 & 15.9 & 97 & 128 & 32.4 \\
\hline 5 & 28.1 & 42.2 & 6.7 & 287.5 & 87.3 & 9.42 & 99.5 & 113.9 & 31.6 \\
\hline 6 & 45.2 & 46.5 & 5.1 & 164.8 & 82.3 & 12.05 & 96.5 & 117.2 & 55.2 \\
\hline
\end{tabular}

Desta forma, o restante do material magnético ainda presente no rejeito, ou seja, o material residual (\%) nesta corrente da polpa pode ser obtida através da fórmula: [1]

Resíduos Magnéticos no Rejeito $=(T 1) \div(T 1+T 2) \times 100 \%$

Sendo que, $\mathrm{T} 1$ = peso, em gramas, do material magnético seco, separado pelo teste de laboratório. T2 = peso, em gramas, do material não-magnético seco, separado pelo teste de laboratório. Tal cálculo demonstra a relação de material magnético que não está sendo separado apropriadamente pelo SM conforme deveria, ou seja, ainda há resíduos magnéticos sendo encaminhados para o rejeito do SM e seguindo para o circuito de concentração do minério. Segundo Wills \& Finch [1], a vazão de alimentação também estabelecida como o peso do concentrado na massa de alimentação da polpa, está correlacionado com o percentual de recuperação do material metálico - sendo estas, uma das medidas para se determinar a eficiência metalúrgica [1]. $\mathrm{P}(80)$ é uma referência para o tamanho das partículas, e é uma medida adotada, em geral, para os testes de granulometria ou curva de moagem, em que $80 \%$ das partículas acumuladas são passantes [1]. Os resultados de distribuição de tamanho são medidos em microns e sua curva é, então, plotada, conforme o gráfico 01 . Os valores de $P(80)$ para cada levantamento (1-6) foram: 150 $\mu \mathrm{m}, 300 \mu \mathrm{m}, 163,6 \mu \mathrm{m}, 146,1 \mu \mathrm{m}, 287,5 \mu \mathrm{m}$ e $164,8 \mu \mathrm{m}$, respectivamente. O modelo de gráfico 01 demonstra a distribuição granulométrica feita com dados medidos no Malvern, sendo este utilizado para gerar as curvas de distribuição granulométrica. Os valores são obtidos pela escala logarítmica no eixo $\mathrm{X}$ e a porcentagem das partículas passantes através da medida de cada peneira (em microns) são representadas no eixo $Y$ [1]. Neste caso, houve uma curva para cada coleta. O teste foi realizado com o material da alimentação, para verificar o tamanho de partículas 
que estariam entrando no SM após a cominuição no moinho de bolas B do circuito primário. Na primeira coleta, o tamanho das partículas da alimentação apresentou resultados compatíveis com as médias referentes ao histórico granulométrico deste $\mathrm{SM}$, além de uma vazão de alimentação dentro da média em relação às outras amostragens.

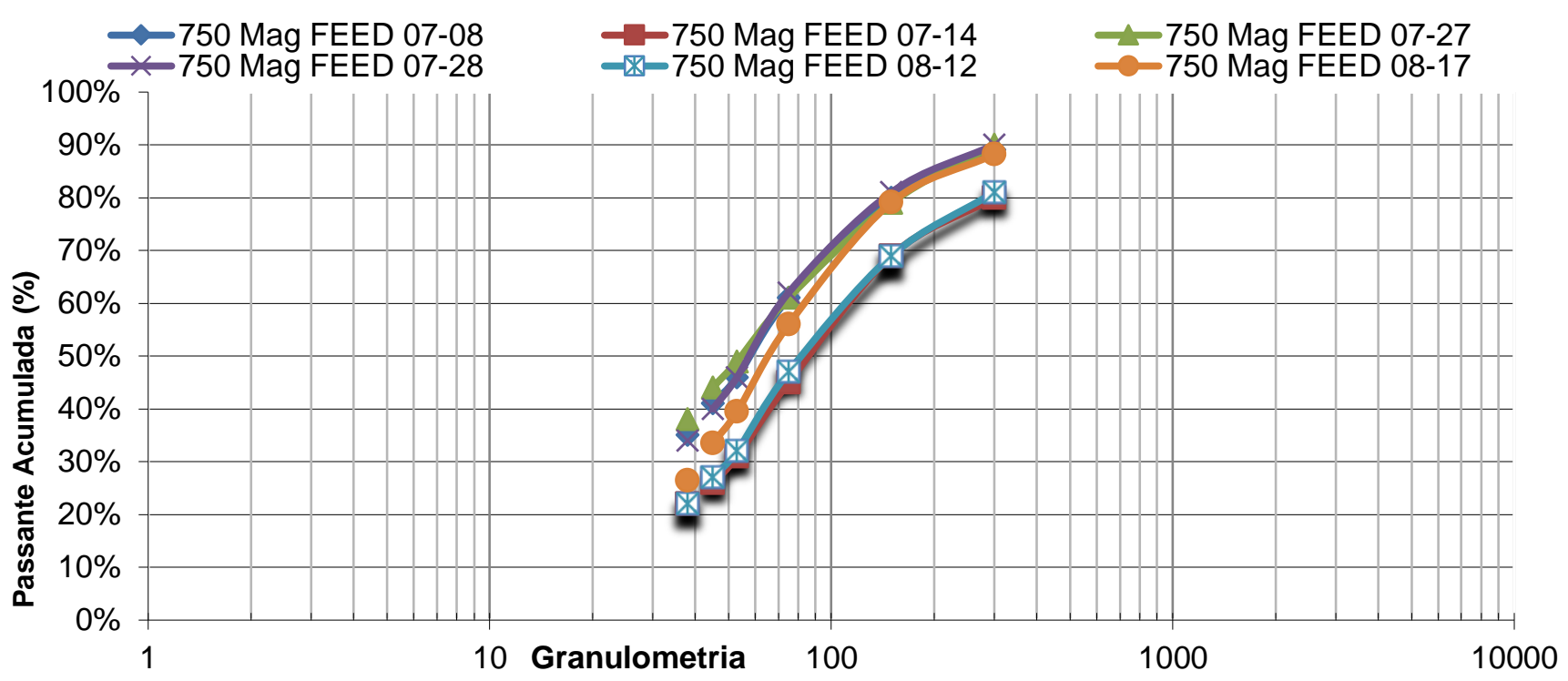

Gráfico 01. Análise de Granulométrica do Feed - P80 em microns (Utilizando Malvern PSD) ${ }^{\star} \mathrm{De}$ acordo com as datas das amostragens

Para cada data de coleta, foram constatados que em cada monitoramento da planta, houveram mudanças no número de linhas (uma ou duas linhas conectadas - lado A e lado B) de alimentação do material que iria para a cominuição (moinho de bolas B), e posteriormente para os SM de 1000 Gauss e 750 Gauss. Na primeira amostragem, apenas o lado A da alimentação da polpa estava em funcionamento. Com isso, a porcentagem de sólidos da alimentação obteve um valor médio em comparação com todos os levantamentos, $27,1 \%$, o que refletiu em uma maior recuperação de material magnético para este mesmo teste executado em laboratório; porém, uma menor recuperação na planta e, consequentemente, um menor valor de eficiência. A relação entre teor e recuperação ou limite de liberação das partículas (limite mineralógico), discutida pelos autores Wills \& Finch [1], estabelece que quanto maior for esta razão, melhor se dará a separação. Esta relação pode ser aplicada neste exemplo. A porcentagem de material magnético no rejeito do SM (tail) afeta o percentual de recuperação magnética do laboratório. $\mathrm{Na}$ primeira amostragem constatou-se que apenas $8,8 \%$ de resíduos magnéticos foram rejeitados de volta para a caixa de descarga, uma quantidade inferior que beneficia a recuperação magnética (teste do laboratório). Esta relação se dará segundo os parâmetros de influência, trazido por Eriez \& Gzrinm (2014) [4] e Svoboda (1993) [5], como o exemplo da susceptibilidade de atração magnética, que cada mineral com um teor magnético se comporta no processo de beneficiamento, como é o caso do minério da planta A. Nesse sentido, observando o volume de material magnético no rejeito, é possível afirmar que a atração magnética esperada da força do campo do SM de estudo se comporta segundo as condições de susceptibilidade magnética destacadas pelos autores [4] [5]. No segundo levantamento, mesmo com uma maior vazão de alimentação (ambas linhas A e B alimentando o SM nesse dia) e maior 
percentual de sólidos na alimentação, não houve uma reflexão positiva na recuperação magnética em laboratório, obtendo apenas $74,3 \%$. Isto se deu porque a britagem primária apresentou um baixo rendimento nesta data, com $\mathrm{P}(80)$ de 300 $\mu \mathrm{m}$; embora a recuperação magnética na planta industrial foi de $98,2 \%$ - devido à maior vazão de alimentação (tph) no circuito para o dia deste levantamento. O fator granulométrico da partícula, segundo [4] e [5] altera a eficiência das colisões.

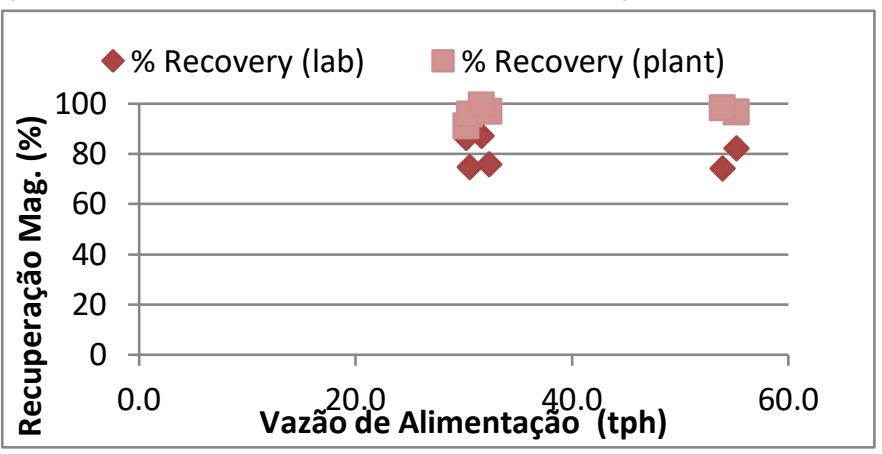

Maiores partículas, como o exemplo desta amostragem, fazem com que as colisões dependam principalmente dos fatores: intercepção, tensão e efeitos da inércia [5]. A porcentagem residual de material magnético deixado no rejeito, da segunda amostragem foi de 15\%, demonstrando que houve uma menor recuperação, no laboratório, do material magnético para os concentrados, $74,3 \%$, conforme os fatores apresentados por Svoboda [5], e demonstrados no Gráfico 02.

Gráfico 02. Recuperação do Material Magnético (\%) para o Concentrado pela Vazão de Alimentação

O terceiro e o quarto levantamento apresentaram resultados similares, com a alimentação (feed) muito diluída - causado pelas mangueiras de água que foram conectadas às linhas de alimentação nos dias respectivos dos levantamentos. Houve um menor percentual de sólidos na alimentação do SM, porém, melhor grau de liberação das partículas do minério em polpa. Partículas menores, como nestes exemplos, a eficiência das colisões se dará através da sedimentação, segundo Svoboda [5]; contudo, o fator de diluição neste caso, é um fator de impedimento para esta medida de eficiência. A relação entre a vazão de alimentação (tph) e recuperação magnética se dá, em geral, de forma crescente, conforme [5] e pode ser visualizada através da relação do gráfico 02 . Contudo, com outras variáveis no sistema, como a pressão da água de lavagem do $S M$ e a velocidade de rotação do tambor do SM, essa relação nem sempre ocorre de forma exata e linear nas operações de uma planta de beneficiamento, de acordo com Queiroz (2005) [6] e conforme gráfico 02 . Neste caso, para esta data de coleta, a pressão da água de lavagem foi inferior ao desejável $(1,4 \mathrm{~kg} / \mathrm{cm} 3)$, e correspondendo a $1 \mathrm{~kg} / \mathrm{cm} 3$ para a média de todas as coletas. $\mathrm{O}$ gráfico 03 demonstra a relação entre a recuperação de material magnético no material concentrado (middlings), comparando-se com o percentual de sólidos para os seis levantamentos. A recuperação da planta foi maior que a recuperação do laboratório, mesmo com o fluxo de alimentação mais diluído devido à maior vazão d'água no $3^{\circ}$ e $4^{\circ}$ levantamentos, o que gerou menos sólidos na polpa. Ainda assim, o rendimento da planta não sofreu significativas perdas na recuperação magnética. $O$ autor Queiroz [6] discute que é necessário que a água de lavagem do SM seja aplicada com uma pressão suficiente no tambor imantado do $\mathrm{SM}$, em um ambiente controlado, quando a porosidade das partículas da polpa tiver uma elevada área de contato (cerca de $30 \%$ da área total). Assim, este fator exercerá influência na recuperação magnética [6] - o que não foi observado durante os levantamentos e pelo histórico do mapeamento da vazão d'água deste separador magnético A. Nesse sentido, quando há um elevado percentual de sólidos ou ambas 
as linhas de alimentação estão em operação, o desempenho demonstrou-se ruim $\left(2^{\mathrm{a}}\right.$ e $6^{a}$ coletas). Os valores medianos da porcentagem de sólidos na polpa, 27,1\% e

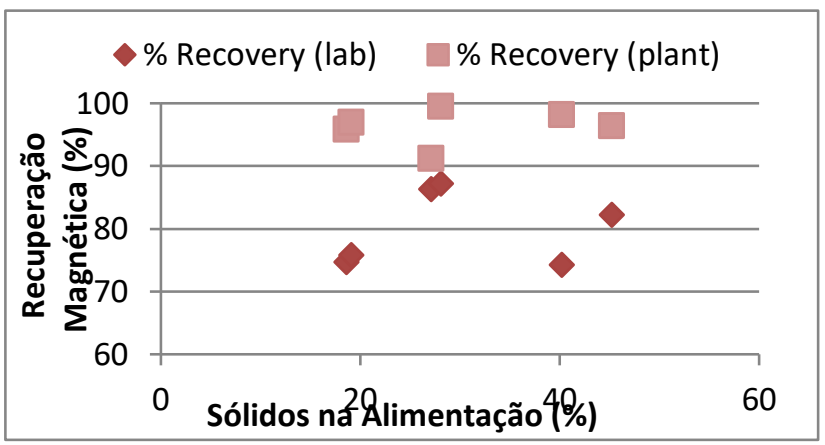

$28,1 \%$ ( $1^{\mathrm{a}}$ e $5^{\mathrm{a}}$ coletas), foram os que representaram melhores recuperações magnéticas no laboratório.

Gráfico 03. Recuperação de Material Magnético (\%) para o material concentrado (Middlings) pela porcentagem de Sólidos na alimentação (Feed)

As recuperações magnéticas de laboratório foram menores na $3^{a}$ e $4^{a}$ coleta, com $74,3 \%$ e $75,9 \%$, respectivamente, pois a porcentagem de resíduos de material magnético conduzido para o rejeito foi maior, $17,7 \%$ e $15,9 \%$. Os valores das recuperações magnéticas na planta foram 95,9\% e 97\% respectivamente, demonstrando, em geral, uma eficiência aceitável. O quinto levantamento demonstrou resultados semelhantes com o primeiro levantamento, apresentando tonelagem dentro dos valores médios e $28,1 \%$ de sólidos na alimentação. Embora 0 $\mathrm{P}(80)$ ou material de moagem demonstrou ter baixo rendimento, com $287,5 \mu \mathrm{m}$, fez com que diminuísse o teor de eficiência, mesmo com boas recuperações magnéticas, conforme exposto em [5]. A porcentagem de material magnético no rejeito também foi menor, $9,42 \%$, o que afetou positivamente a recuperação no laboratório, demonstrando que a maior parte do material magnético está sendo separada do material não-magnético, e com isso, irá aumentar o rendimento da próxima etapa de concentração.

A sexta amostragem esteve com ambas as linhas de alimentação (feed) A e B em funcionamento nesses dias, o que elevou o percentual de sólidos na alimentação, $45,2 \%$. Além disso, a granulometria das partículas no feed esteve entre valores médios para os padrões de operação deste SM, conforme seu histórico de funcionamento, obtendo $164,8 \mu \mathrm{m}$. Ainda, houve uma boa recuperação de material magnético no laboratório em comparação com a planta. Consequentemente, os valores para a eficiência de separação também foram médios. A porcentagem de material magnético no rejeito foi um pouco acima do ideal, com 12,05\% provavelmente devido a elevada vazão de alimentação (tph). As informações da granulometria ou de cominuição, sozinhas, não afetam a recuperação magnética [2]; e, consequentemente, o rendimento do SM na planta. Conforme Wills e Finch (p.06, 2016) [1], deve ser notado que um alto grau de liberação ou dissociação de elementos químicos durante a quebra pela britagem e moagem, não é sempre necessária, e pode ser até indesejável em alguns casos. Segundo os autores [1, 6], desde que uma densidade pronunciada ou a diferença na susceptibilidade magnética forem aparentes entre as partículas "presas" ao minério e as partículas livres de ganga, a separação é passível de se ocorrer. Este fato pode ser observado no gráfico 04 e os valores da tabela 02 . Além disso, o gráfico 05 demonstra relação entre a porcentagem de sólidos na polpa pela granulometria ou valor de $\mathrm{P}(80)$ em microns. Os resultados estão divididos entre as granulometrias médias de 156 $\mu \mathrm{m}$ e $300 \mu \mathrm{m}$. Conforme os resultados, esperou-se que o concentrado obtivesse a 
maior densidade ou percentual de sólidos, pois o material magnético está sendo atraído para ele.

Tabela 02. Percentual Metálico em cada ponto de Coleta

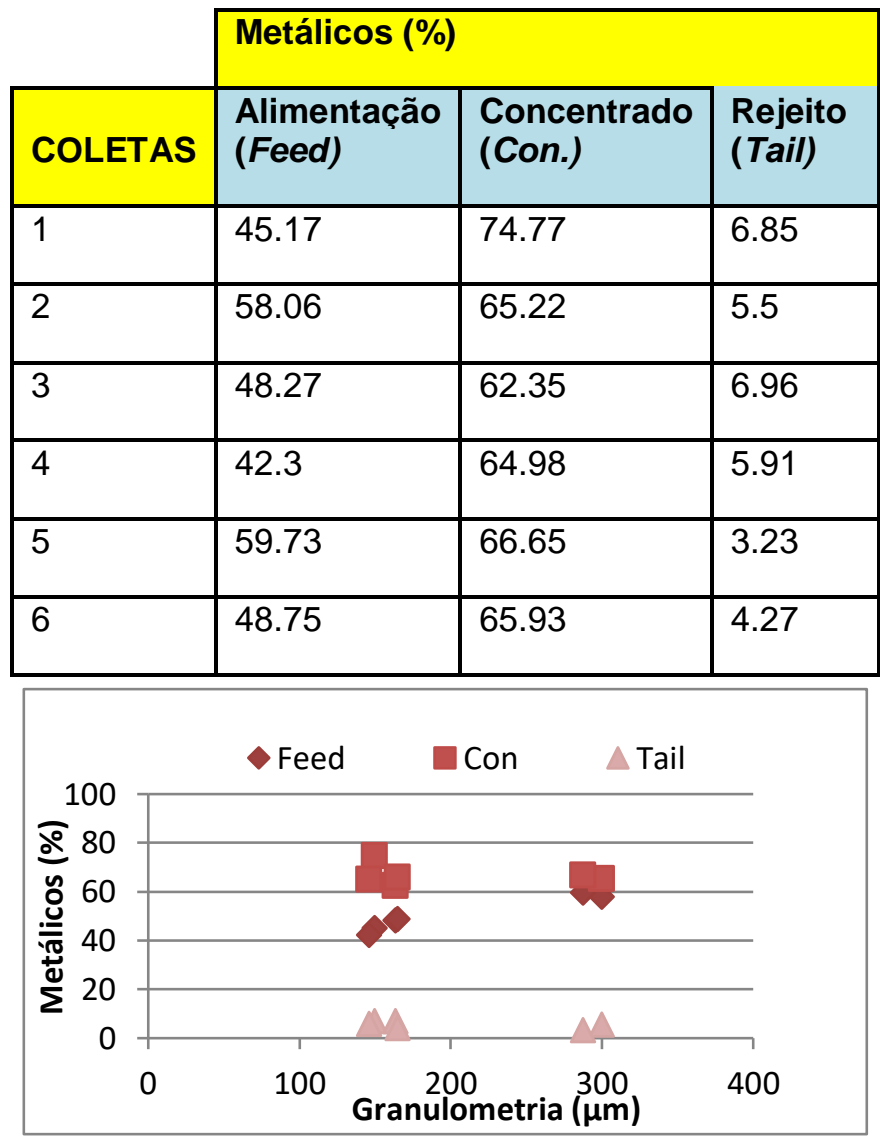

Gráfico 04. Relação entre Material Metálico (\%) pela Granulometria P(80) em $\mu \mathrm{m}$

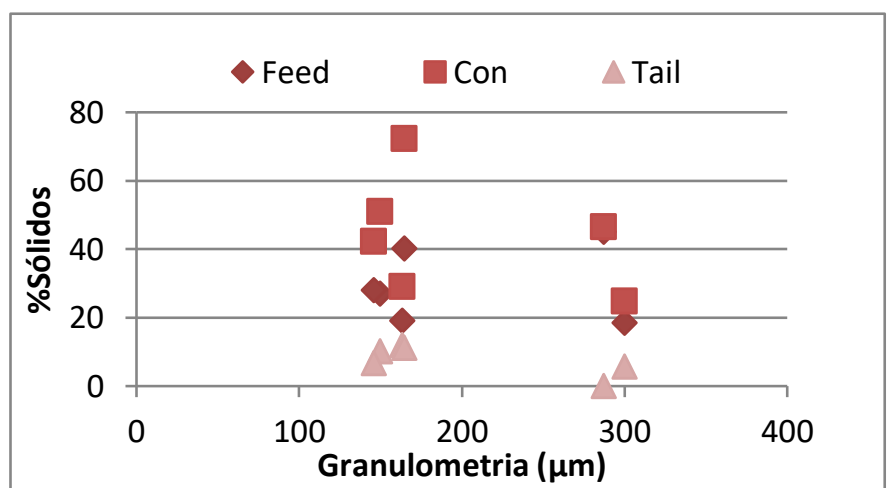

Gráfico 05. Percentual de Sólidos pela Granulometria em P80 $(\mu \mathrm{m})$

Para todos os seis levantamentos, a recuperação magnética média para 0 concentrado, durante a realização do teste de laboratório magnético, foi de $80 \%$. A recuperação média de material magnético foi de $96,3 \%$ sendo que este resultado foi analisado pelo balanceamento metalúrgico utilizando o software Bilmat. A eficiência do SM estudado obteve média correspondente a $120,8 \%$. Para as $2^{\mathrm{a}}$ e $5^{\mathrm{a}}$ amostragens, a média granulométrica de P80 foi de $293 \mu \mathrm{m}$. O percentual metálico foi de $59 \%$ para a alimentação (feed) e de $66 \%$ para o concentrado (con.), e um valor mais baixo (4,4\% em média) para o rejeito (tailings). Além disso, no segundo e quinto levantamento, as porcentagens de recuperações magnéticas da planta 
industrial, apresentaram os melhores resultados, com respectivamente, $98,2 \%$ e $99,5 \%$, demonstrando que a susceptibilidade magnética nestes dias foi mais alta e independente do tamanho da granulometria. Outros fatores foram mais influenciadores do que a granulometria nestes casos. A média da eficiência esteve dentro dos parâmetros aceitáveis para todos as amostragens; embora, o menor percentual de eficiência da planta esteve também relacionado ao rendimento em laboratório. O percentual de recuperação magnética da planta demonstrou bons resultados para todos os levantamentos (1-6), independentemente da taxa de eficiência. A medida de eficiência foi calculada utilizando os dados da Tabela 01, nas colunas referentes a "Recuperação Magnética no Material Concentrado" da planta de beneficiamento e do teste em laboratório. A eficiência é então, obtida através da divisão simples destes dois valores, recuperação magnética da planta sob a recuperação magnética do laboratório, e o valor é dado em porcentagem. Percebese através do Gráfico 06 que os percentuais de recuperação estão acumulados entre duas unidades da vazão de alimentação (tph). Este resultado deve-se ao fato de que estes valores são as médias do fluxo de alimentação diário para esta planta de beneficiamento, ou seja, a alimentação obedece a uma constância entre

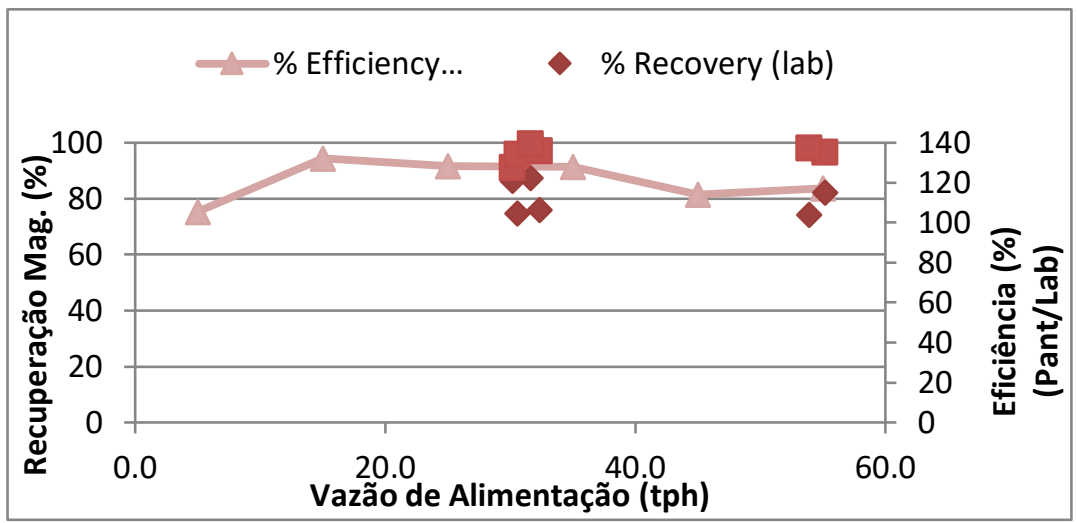

aproximadamente $30 \mathrm{tph}$, e nos dias em que duas linhas de alimentação foram conectadas, o valor sobe para aproximadamente $53 \mathrm{tph}$, fazendo com que os valores de recuperação fiquem acumulados entre estas medidas de vazão, conforme os dados da Tabela 01 e Gráfico 06.

Gráfico 06. Recuperação de Material Magnético (\%) para o Material Concentrado e Unidade de Eficiência da Planta (\%) pela Vazão de Alimentação (tph)

De acordo com a literatura [1-6], histórico de outras amostragens conduzidas neste separador magnético $A$, e manuais dos fabricantes de separadores magnéticos, existem outros parâmetros técnicos da sua configuração que podem afetar 0 desempenho destes equipamentos, e, assim, influenciar os resultados de sua eficiência. Os mais importantes são: força do ímã; qualquer limpeza de material nas linhas de alimentação dos SM (adição de água e ou contaminantes) na planta de tratamento. Outras configurações técnicas dos SM, como por exemplo: abertura entre o lábio e o tambor no seu interior; espaçamento entre o tambor (polia magnética) e o fundo do tanque do SM; número de placas de descarga no tanque; velocidade (rotações por minuto) do tambor ou polia magnética, são especificações técnicas que podem modificar os resultados do rendimento dos SM dentro da operação de beneficiamento. Todavia, nesta pesquisa, estes parâmetros técnicos do fabricante não foram analisados, por isso, não podem ser comparados quantitativamente ou qualitativamente neste estudo para o separador magnético $A$.

\section{CONCLUSÃo}


Após compilar os resultados de todas as coletas, pode-se concluir que o separador magnético secundário de 750 Gauss recupera o material magnético de forma eficiente, seja com o funcionamento de uma linha ou duas linhas de alimentação. Além disso, apesar do menor ou maior percentual de sólidos e distribuição final de tamanho de partícula na alimentação (medidos pelos ensaios de P80), o SM de estudo apresentou um rendimento satisfatório. Os resultados observados mostraram no geral, uma melhor taxa de recuperação magnética na planta em comparação com os testes de laboratório, pois, em todos os resultados dos levantamentos in loco, o percentual de eficiência ou rendimento metalúrgico foi superior a $100 \%$. Sendo assim, constatou-se que os todos os parâmetros influenciadores da planta não puderam ser reproduzidos em laboratório, como a vazão e pressão da água de lavagem, o que poderia influenciar um rendimento final de separação magnética nestes ensaios.

Com base nos resultados e discussões, uma maior quantidade de sólidos ou demasiada taxa de alimentação (tph) dentro do circuito primário $\mathrm{A}$, mostrou ter um impacto negativo sobre as recuperações magnéticas, e consequentemente, na eficiência do equipamento, conforme previsto pelos autores [1] e [2]. Em contrapartida, um porcentual muito inferior de sólidos na alimentação ou demasiada diluição da polpa (excesso de água na corrente de alimentação), faz com que o SM não receba a quantidade de sólidos apropriadamente ao tempo de rotação e velocidade do tambor deste equipamento, e consequentemente, prejudicando sua eficiência metalúrgica. Conclui-se com esta pesquisa que, outros levantamentos devem ser conduzidos em operações no circuito $A$, executando a mesma metodologia destas amostragens nas duas linhas de alimentação, em separado. Desta forma, será possível comparar, especificamente, a influência das redes de alimentação (fluxo, vazão, contato com impurezas, dentre outros aspectos) como sendo um parâmetro no rendimento deste equipamento $A$, e então, fazer o seu controle adequado. Além disso, faz-se necessário realizar os mesmos ensaios de caracterização em torno dos SM primários de influência (1000 Gauss) neste circuito, a fim de se comparar os resultados obtidos em campo na planta industrial, com os resultados dos ensaios em laboratório.

\section{Agradecimentos}

Agradecimentos especiais ao órgão de amparo à educação e pesquisa, o Conselho Nacional de Desenvolvimento Científico e Tecnológico (CNPq), pela concessão da bolsa de Graduação-Sanduíche entre setembro de 2015 e dezembro de 2016 de intercâmbio, número do processo 213612/2014-3 SWG, e que permitiram-me desenvolver esta pesquisa.

\section{REFERÊNCIAS}

1. Wills, Barry A., Finch, James, A. Wills' Mineral Processing Technology: An Introduction to the Practical Aspects of Ore Treatment and Mineral Recovery. $8^{\underline{a}}$ ed. UK: Elsevier; 2016.

2. Svoboda, J, Fujita, 2003. Recent developments in magnetic methods of material separation. Miner. Eng. 16 (785-792), 786-787.

3. Rousell, D.H., 1983. Nature and Origin of Mineralization Inside Sudbury Basin, Ontario. Ontario Geological Survey Open File Report 5443. pp.7-9.

4. Eriez, Gzrinm, 2014. Reliable WHIMS with Maximum Recovery. Eriez Manufacturing Company, Erie, Pa, USA, pp. 1-12. 
5. Svoboda, J., 1993. The effect of magnetic field strength on the efficiency of magnetic separation. Miner. Eng. 7 (747-757), 749-750.

6. Queiroz, A. Treinamento de Mineralogia: Interpretação mineralógica aplicada em definição de rota de processo de minério de ferro. Mariana-MG: Vale, 2005. 